\title{
Improving consistency for a Mefenamic acid immediate release formulation
}

Elke Prasad ${ }^{a, b}$, John Robertson ${ }^{a, b}$, Gavin W. Halberta, b

${ }^{a}$ EPSRC Future Manufacturing Research Hub, University of Strathclyde, Technology and Innovation Centre, 99 George Street, Glasgow, G1 1RD, UK

${ }^{b}$ Strathclyde Institute for Pharmacy and Biomedical Sciences, University of Strathclyde, 161 Cathedral Street, Glasgow, G4 ORE, UK 


\section{Abstract}

The objective of this study was to develop an immediate release dose form containing $250 \mathrm{mg}$ Mefenamic acid (MFA) presented as a crystalline solid dispersion in order to achieve improved consistency in drug release through a simplified formulation compared to a commercial product. An MFA-Soluplus ${ }^{\circledR}$-Sorbitol polymer matrix was developed using an HME process based on rheological screening assays of physical mixtures. The physico-chemical properties of these formulations were assessed by thermal analysis, FTIR, mechanical testing and SEM image analysis, confirming the crystalline character and stable polymorphic form I of the API in the polymer matrix. A faster release and a significant improvement in consistency $( \pm 6 \%)$ of drug release was observed compared to a commercially available MFA product $( \pm 17 \%)$ ( $250 \mathrm{mg}$ capsule). This study illustrates advantages of applying a structured development program aimed at retaining API physical properties in the final dosage form.

Keywords: Extrusion, Solid dosage form, Oral drug delivery, Solid dispersion, Dissolution, Formulation

\section{Introduction}

Mefenamic acid (MFA) is a non-steroidal anti-inflammatory drug which is widely used in the treatment of rheumatoid arthritis and menstrual disorders. Three crystalline forms have been reported for MFA, with form II and III presenting metastable states ${ }^{1}$. MFA is classed as a BCS class II drug ${ }^{2}$ exhibiting low solubility and high permeability. Within this class, MFA drug absorption is considered to be a dissolution rate limited (class Ila) ${ }^{3}$. Although formulation design for class Ila drugs can achieve complete oral absorption from a standard solid oral dosage form containing crystalline MFA, factors affecting drug release such as particle size, surface area and wettability will be critical in achieving this ${ }^{3,4}$.

Hummel and Buchmann investigated the impact of MFA particle size on the dissolution and bioavailability of tablets, and found that particle size reduction and resulting increased surface area of MFA resulted in a significant increase in absorption and bioavailability 5 . Further investigations into the physico-chemical properties of MFA after dry milling showed that the increased initial dissolution rate was not only related to the increase in surface area, but also an increase in amorphous drug content ${ }^{6}$. MFA form changes to polymorphic forms II or III were not observed.

MFA drug product is commercially available as a powder filled capsule formulation $(250 \mathrm{mg})$ and as a tablet formulation $(500 \mathrm{mg})$. The capsule formulation contains multiple excipients: lactose monohydrate, gelatine, sodium starch glycollate, sodium lauryl sulfate. The capsule shell also contains patent blue, erythrosine, yellow iron oxide and titanium dioxide. Various formulation approaches aiming to address the low solubility and variable bioavailability of MFA have been reported, such as micellar solutions ${ }^{7}, \beta$-cyclodextrin complexes ${ }^{8}$, self-emulsifying drug-delivery systems (SEDDS ${ }^{9}$ and SMEDDS ${ }^{10,11}$ ) and solid dispersions ${ }^{12-15}$.

Solid dispersions are one of the most promising strategies to improve the oral bioavailability of poorly water-soluble drugs. In these types of formulations, the carrier (polymer matrix) can contain the drug in crystalline form, amorphous form, or can be molecularly dispersed ${ }^{16}$. By reducing drug particle size to the absolute minimum, drug wettability and bioavailability may be significantly improved ${ }^{4,13}$.

Solid dispersions containing MFA have been prepared by different methods, such as the melt method $^{15,17}$, solvent evaporation method ${ }^{13}$ or hot melt extrusion ${ }^{12,14}$. Solid dispersions containing MFA prepared by hot melt extrusion achieved significantly higher (amorphous) drug loadings $(40 \% \mathrm{w} / \mathrm{w})$ compared to other methods ${ }^{12}$. Although amorphous solid dispersion (ASD) can provide better aqueous solubility than their crystalline counterpart ${ }^{18}$, the internal increased free energy can provide a thermodynamic driving force for phase separation and crystallisation ${ }^{19}$. Product performance upon storage of these formulations may be impaired or fail product specification due to these events.

The aim of this study was to improve the consistency of MFA drug release in an immediate release (IR) dose form compared to commercial capsules. A simplified formulation, based on MFA dispersed 
in a polymer matrix, was selected preventing the need for multiple excipients. A crystalline solid dispersion (CSD) formulation prepared by hot melt extrusion containing up to $50 \%$ (w/w) MFA was chosen, in order to avoid potential physical stability issues of ASDs.

In this study the process and formulation development of a CSD in a polymer matrix amenable to post processing steps (such as 3D printing or injection moulding) is presented. This work forms part of the wider aim of the EPSRC Future Manufacturing Research HUB at CMAC to implement integrated continuous, laboratory scale manufacturing platforms. In this instance, crystal engineering of a model drug, Mefenamic acid (MFA), coupled with polymer processing steps to deliver optimised physical properties for biopharmaceutics performance.

In this study a CSD of Mefenamic acid in a Soluplus ${ }^{\circledR}$-Sorbitol polymer matrix was developed using an HME process. The physico-chemical properties of these formulations were assessed and their product performance compared to a commercially available MFA product (250mg capsule, Pharmavit Limited, UK).

\section{Materials and Methods}

\subsection{Materials}

Soluplus ${ }^{\circledR}$ polymer was donated from BASF (Ludwigshafen, Germany). Mefenamic acid (MFA), Sorbitol Emprove Parteck SI 150, Sodium dodecylsulphate Ph Eur (SDS),

Tris(hydroxymethyl)aminomethane (Tris) and Trifluoroacetic acid (TFA) were purchased from Sigma Aldrich (Gillingham, UK). Hard gelatine capsules, Licap ${ }^{\circledR}$ size 0, were donated from CR UK Formulation unit, University Strathclyde (Glasgow, UK). Ethanol absolute, Phosphoric acid $85 \%$ for HPLC, Sodium hydroxide and hydrochloric acid was purchased from VWR (Lutterworth, UK). Commercial Mefenamic acid product, $250 \mathrm{mg}$ Mefenamic acid capsules were purchased from Pharmavit Limited (PVL) (Birmingham, UK). Mefenamic acid form II powder was prepared in house.

\subsection{Mefenamic acid form II}

Form II of MFA was prepared in a N,N-dimethylformamide solution. MFA form I was dissolved at 200 $\mathrm{mg} / \mathrm{g}$ in N,N-di-methylformamide stirring at $400 \mathrm{rpm}$ at $65^{\circ} \mathrm{C}$ until fully dissolved. The clear solution was cooled in a $-20^{\circ} \mathrm{C}$ freezer and held at this temperature until the Mefenamic acid was crystallized. The crystals were filtered and dried over night at $65^{\circ} \mathrm{C}$ to obtain MFA form II. MFA form II was used as a reference in FTIR measurements.

\subsection{Formulations}

Powders were passed through a $1 \mathrm{~mm}$ mesh sieve prior to weighing. A physical mixture (PM) of Soluplus ${ }^{\circledR}$ containing $15 \%$ (w/w) Sorbitol was prepared (SOL15SORB) and a mixture containing $50 \%$ (w/w) MFA in SOL15SORB (50MFA-SOL15SORB) was prepared by mixing in a Pharmatech bin blender AB-015 equipped with a $1 \mathrm{~L}$ vessel for $150-200 \mathrm{~g}$ samples. Blending was carried out at 17 $\mathrm{rpm}$ with an agitator speed of $100 \mathrm{rpm}$ for $10 \mathrm{~min}$.

\subsection{PSD}

Particle size analysis of Mefenamic acid was performed using the Qic/PIC, dynamic imaging system, equipped with the Rhodos attachment from Sympathec (Clausthal-Zellerfeld, Germany). Analysis was performed with the M7 lens system (4-2888 $\mu \mathrm{m}$ ) with a frame rate of $15 \mathrm{~Hz}$, an autofocus period of $85 \mathrm{~s}$ and an analysis period of $300 \mathrm{~s}$. A gap setting of $0.5 \mathrm{~mm}, 0.5$ bar and $20 \%$ vibration for the Rhodos attachment were used. Image analysis was performed with the QICPIC Sensor Control Windox software (V. 5.9.0.0) based on a minimum of 700000 particles using the equivalent perimeter of a circle (EQPC) calculation mode. 


\subsection{Rheology}

Physical mixtures of Mefenamic acid, Soluplus ${ }^{\circledR}$ and Sorbitol were analysed on a Haake Mars III rotational rheometer equipped with a $25 \mathrm{~mm}$ diameter parallel plate geometry. $500 \mathrm{mg}$ of powdered sample were compacted under vacuum with a compaction force of 2 tonnes for 2 minutes using a manual hydraulic press to prepare round, $25 \mathrm{~mm}$ diameter discs for analysis.

Zero gap height calibrations were performed prior to rheological analysis'. Measurements were performed in the linear visco-elastic region (LVR) of materials.

Oscillatory temperature sweep: Sample discs were loaded at $160^{\circ} \mathrm{C}$ and equilibrated for 5 minutes. Temperature sweeps were performed from $160^{\circ} \mathrm{C}$ to $110^{\circ} \mathrm{C}$ temperature, with a constant deformation of $0.5 \%$ at a frequency of $1 \mathrm{~Hz}$. The gap setting was normal force controlled at $0.1 \mathrm{~N}$.

Oscillatory frequency sweeps: Sample discs were loaded at test temperature and equilibrated prior to analysis. Frequency sweeps were performed with a constant deformation of $0.5 \%$ across a frequency range from $0.1-100 \mathrm{~Hz}$. Frequency sweeps were performed at $140{ }^{\circ} \mathrm{C}, 130^{\circ} \mathrm{C}, 120^{\circ} \mathrm{C}$.

\subsection{HME}

Hot melt extrusion was performed on a Process 11 (Thermo Fisher, Karlsruhe, Germany) twin screw extruder with a length $(L)$ to diameter $(D)$ ratio of $403 / 4$ equipped with a $1.6 \mathrm{~mm}$ round die. The screw configuration is depicted in Figure 1 and consisted of: 14 feed screws $-6 \times 60^{\circ} \mathrm{F}$ mixing elements $-7 \mathrm{x}$ feed screws $-3 \times 30^{\circ} \mathrm{F}, 3 \times 60^{\circ} \mathrm{F}, 4 \times 90^{\circ}$ mixing elements -13 feed screws - discharge element. A 2000 Series melt pressure transducer with a pressure limit of 100 bar (Terwin Instruments Ltd, Bottesford, UK) was attached to the HME die zone. Physical mixtures of formulations were fed into the HME process using a Brabender Loss in weight (LIW) feeder machine (type DDW-N-MT) equipped with twin concave screws (TC12/12) (Brabender, Duisburg, Germany) and calibrated for maximum output prior to processing. HME process torque data was expressed as $\%$ of maximum torque $(12 \mathrm{Nm})$. Die swell of extrudates was assessed by measuring the filament diameter using digital callipers $(0.01 \mathrm{~mm}$, Axminster, Devon, UK). A minimum of 5 measurements were performed per filament.

\subsection{DSC}

Thermal analysis of physical mixtures and extrudates was performed on a DSC214 Polyma (Netzsch, Selb, Germany). Sampels were accurately weighed into $25 \mu \mathrm{L}$ Aluminium crucibles and sealed with a pierced lid. Extrudate samples were hand cut to pellets prior to analysis. $5-10 \mathrm{mg}$ of sample were analysed at $20{ }^{\circ} \mathrm{C} / \mathrm{min}$ heating rates from $0-250{ }^{\circ} \mathrm{C}$ using Helium purge gas at $40 \mathrm{~mL} / \mathrm{min}$ and Helium protective gas at $60 \mathrm{~mL} / \mathrm{min}$. The method used inverted, pierced lids to allow more space for extrudate samples. The reference crucible was also analysed with an inverted lid.

\subsection{FTIR}

FTIR analysis of raw materials, physical mixtures and extrudates was carried out on a Bruker Tensor II spectrophotometer equipped with a Platinum ATR (attenuated total reflectance) accessory. Interferogramm position and amplitude checks were performed prior to analysis. FTIR scans were performed using a $\mathrm{KBr}$ beam splitter with a $6 \mathrm{~mm}$ aperture and a $7.5 \mathrm{KHz}$ scanner velocity. Samples were analysed with 16 scans at a resolution of $2 \mathrm{~cm}^{-1}$ and data recorded for wavenumber $4000-400$ $\mathrm{cm}^{-1}$.

\subsection{Mechanical testing}

Mechanical properties of filaments were tested on a Texture Analyser TA-XT (Stable Micro Systems, Godalming, UK) equipped with a mini 3-point bend rigen. Filaments samples were cut to a length of 2 $\mathrm{cm}$. Digital callipers $(0.01 \mathrm{~mm}$, Axminster, Devon, UK) were used to measure the length and diameter of the samples, which were placed centrally on the two lower support beams with a gap of $0.8 \mathrm{~cm}$. The upper blade speed was set to $0.5 \mathrm{~mm} / \mathrm{sec}$ until a trigger force of $0.049 \mathrm{~N}$ was achieved. Testing 
was conducted with a blade speed of $0.02 \mathrm{~mm} / \mathrm{sec}$ and a total displacement of $4.5 \mathrm{~mm}$. Data acquisition and analysis was performed with Exponent software (version 6.1.11.0) with a rate of 25 points per second. Five replicates were tested for each sample.

Recorded data was plotted as a Stress -Strain graph and the Flexural modulus was calculated as the slope of the stress strain graph between $0.05 \%$ and $0.25 \%$ strain. In addition, the maximum stress and associated elongation were determined. To determine the break point, data was re-processed by applying a Savitzky-Golay filter, generating the first derivative of the stress data. The minima in the resulting curve (first derivative of Stress-Strain) represents the break point of the filament. The area under the curve to the break point was reported as the Modulus of toughness.

\subsection{SEM}

Extrudate samples were added to aluminium stubs with adhesive carbon tabs, both with side of extrude and cut face exposed. Samples were sputter coated with $20 \mathrm{~nm}$ gold layer to minimise charging in the SEM. Samples were then placed under vacuum for 2 minutes prior to transfer to SEM for analysis using a TM4000Plus SEM (Hitchi, Tokyo, Japan). The SEM was operated at beam voltage $10000 \mathrm{eV}$ with a probe current setting of 2 , standard vacuum level (M) and with data collected in backscattered electron mode at magnifications of 30x, 500x, and 2000x.

\subsection{Content analysis - HPLC}

Content analysis of extrudate samples was performed on an Agilent 1100 LC system equipped with G1315A Diode Array Detector. Analysis was carried out on a reversed phase C-18 stationary phase (Kinetex2.6u C18 50x3 mm) using UV detection and quantification at $278 \mathrm{~nm}$ wavelength. A gradient method (Table 1) was used with mobile phase (MP) A $0.5 \%$ TFA in $\mathrm{dH}_{2} \mathrm{O}$ and MP B $0.5 \%$ TFA in HPLC grade Acetonitrile. MFA standard and extrudate sample solutions were prepared at $200 \mu \mathrm{g} / \mathrm{mL}$ using a diluent composed of $70 \%$ Ethanol $-30 \% \mathrm{dH}_{2} \mathrm{O}(\mathrm{v} / \mathrm{v}) .10 \mu \mathrm{L}$ of sample were injected and analysed at $30^{\circ} \mathrm{C}$ with a flow rate of $1.47 \mathrm{~mL} /$ min collecting UV Absorbance data at discrete wavelengths $(220,254,278,354 \mathrm{~nm})$ and a Diode Array spectrum from $190-400 \mathrm{~nm}$. System suitability test and bracketing standards were run to ensure the validity of the analysis. The HPLC method was validated for the presence of the Soluplus ${ }^{\circledR}{ }_{-}$Sorbitol polymer matrix, across an MFA concentration range from $50-300 \mu \mathrm{g} / \mathrm{mL}$, showing good linearity with an $r^{2}=0.9997$ and recovery values ranging from $98.0-100.8 \%$.

\subsection{Release testing USP 37}

Product performance testing was performed using a ADT8i Dissolution bath (USP I, basket) apparatus with a closed loop setting and a T70+ UV/Visible Spectrophotometer (Automated Lab Systems, Wokingham, UK). The dissolution assay was performed in $1000 \mathrm{~mL} 0.05 \mathrm{M}$ Tris dissolution buffer $\mathrm{pH} 9$ (USP 37 Mefenamic acid capsules) at $100 \mathrm{rpm}$ and $37 \pm 0.5^{\circ} \mathrm{C}$. Samples were filtered through a $0.2 \mu \mathrm{m}$ filters prior to UV analysis. Sampling was performed at 5 minute intervals with a flush volume of $20 \mathrm{~mL}$ and a flush speed of $20 \mathrm{~mL} / \mathrm{min}$. UV analysis was performed at $286 \mathrm{~nm}$ using $1 \mathrm{~mm}$ path length flow cell cuvettes. Quantification of MFA was validated for the presence of excipients (Soluplus ${ }^{\circledR}$, Sorbitol) across an MFA concentration range of $100-300 \mu \mathrm{g} / \mathrm{mL}$, showing good linearity with $r^{2}=0.9996$ and recovery values of $97.5-105.6 \%$.

Commercially available Mefenamic acid capsules 250mg (Pharmavit Ltd, UK) were analysed and the '\% release based on Label Claim' reported. 50MFA-SOL15SORB extrudate was hand cut to small pellets and filled into hard gelatine capsules. The capsule fill weight was equivalent to $250 \mathrm{mg}$ MFA and the '\% release normalised to fill weight' reported.

Dissolution profiles were compared based on the difference (f1) and similarity (f2) factor method ${ }^{21}$. For curves considered similar f1 ranges from 0 - 15 and f2 values from $50-100$. 


\section{Results and discussion}

\subsection{Particle size and powder blend characterisation}

The particle size distribution of Mefenamic acid raw material is shown in Table 2. The determined API content of $48.2 \%(\mathrm{w} / \mathrm{w})$ was slightly lower than the theoretical powder blend composition. The loss of approximately $2 \%(\mathrm{w} / \mathrm{w})$ MFA at elevated temperatures is possibly due to the phase transition of MFA via sublimation ${ }^{22,23}$ (via the HME vent and from the hot extrudate exiting the die) and the high vapour pressure of MFA at elevated temperatures ${ }^{22}$.

\subsection{Rheology - physical mixtures}

In order to retain the crystalline nature of MFA and prevent MFA phase transitions from form I to form II, the lowest extrusion temperature was sought for HME processing. Rheological properties of the physical mixture as a function of temperature and shear (angular frequency) were investigated and used to guide selection of HME processing temperature. The oscillatory temperature sweep of SOL15SORB PM showed complex viscosity values ranging from $1.7^{*} 10^{3} \mathrm{Pas}$ at $160{ }^{\circ} \mathrm{C}$ to $2.4 * 10^{5}$ Pas at $110^{\circ} \mathrm{C}$ (Figure 2). The complex viscosity was lower than Soluplus ${ }^{\circledR}$ polymer only, which was due to the plasticising effect of sorbitol melting and dissolving in the polymer during the sample equilibration step at $160{ }^{\circ} \mathrm{C}$ prior to analysis. The analysis of 5OMFA-SOL15SORB PM saw poor reproducibility, which was very likely due to the drug not being evenly dispersed in the sample because a) the pre-measurement temperature equilibration step did not facilitate MFA dissolution in the polymer (seen as particles in the polymer post analysis) and b) poor sample adhesion to the parallel plate geometry due to the lipophilic nature of MFA. This may have resulted in the sample going through the Temperature sweep as a multiphase system.

Kolter et al reported complex viscosity values of $8 * 10^{2}$ to $10^{4}$ Pas the most suitable for extrusion on small scale extruders, such as the Thermo 11 (with the upper limit dictated by the maximum torque limit of the extruder) ${ }^{24}$. Based on the upper limit of this range, the corresponding extrusion temperature for SOL15SORB PM was identified as $134^{\circ} \mathrm{C}$.

Due to their macromolecular structure, polymers are viscoelastic materials: their properties lie between the properties of pure elastic solids and viscous fluids ${ }^{25}$. When polymers are deformed, the relationship between stress and strain are time dependant. Rheological assessment of polymer melts in oscillation mode allows to measure the energy stored in materials upon deformation (Elastic/storage modulus, G') and the energy that is lost via dissipation (Viscous/loss modulus, G"). The relationship between G" and G' shows the contribution of viscous and elastic behaviour of the polymer under given conditions ( $\tan \delta=G^{\prime \prime} / G^{\prime}$ ).

Based on the predicted processing temperature of $134{ }^{\circ} \mathrm{C}$ for SOL15SORB PM from temperature sweep experiments and in order to keep the HME processing temperature low (to retain form I and prevent dissolution of the API in the polymer), frequency sweeps were performed at a range of temperatures $\left(120,130\right.$ and $\left.140^{\circ} \mathrm{C}\right)$ around the estimated process temperature. Shear thinning behaviour was observed for SOL15SORB PM, seen as a decrease in complex viscosity with increasing angular frequency (Figure $3 \mathrm{~A}$ ).

At low angular frequencies, the viscous behaviour (G") of SOL15SORB PM dominated. With increasing angular frequency, an increase in both, storage and loss modulus, was observed (Figure $3 \mathrm{~B})$. At temperatures at the higher end of the identified HME processing temperature range $\left(140{ }^{\circ} \mathrm{C}\right)$ equal contribution of viscous and elastic behaviour was observed at high angular frequencies. At the lower end of HME processing temperature range, an increase in angular frequency saw a change in the relationship of G" and G', with the elastic contribution dominating the overall visco-elastic behaviour of the polymer (G'> G"). The G' / G" cross-over point was seen at lower angular frequency at $120^{\circ} \mathrm{C}$ compared to higher angular frequency at $130{ }^{\circ} \mathrm{C}$ (Figure 3 , Figure $S 1$ ). At temperatures below $140^{\circ} \mathrm{C}$, the polymer system showed increased sensitivity to shear induced increase of the storage modulus (elastic behaviour). An increase in elastic behaviour of a polymer system may be associated with an increase in die swell, torque or pressure during the extrusion process. 
In order to identify ideal extrusion conditions, the following considerations in relation to shear and temperature were made: $A$ compromise in the process temperature was sought, with the temperature low enough to retain MFA form I and prevent MFA dissolution in the polymer, but high enough to reduce the complex viscosity sufficiently to process on a small scale extruder. Although the observed shear thinning behaviour may allow processing at lower temperatures, low screw speed and feed rate was sought in order to reduce problems associated with the elastic behaviour of the polymer and allow for slow post processing steps. Based on these findings and considerations, the starting point for HME processing trials was $140^{\circ} \mathrm{C}$.

\subsection{HME}

$\mathrm{HME}$ trials for the polymer matrix only were started with a process temperature of $140{ }^{\circ} \mathrm{C}$. A step-wise reduction in process temperature was sought to identify the lowest barrel and product temperature where extrusion was possible. Extrusion on the Process 11 is limited by a maximum torque of $12 \mathrm{Nm}$ and die pressure of 100 bar. In addition, the impact of screw speed on process (torque, pressure) and product parameters (product temperature) were assessed and compared to the rheological screening assay results.

At $140{ }^{\circ} \mathrm{C}$ an increase in screw speed to 100 and 200 rpm saw a decrease in die pressure that remained constant at higher screw speeds (Figure 4). Torque values showed an initial increase, and decreased at screw speeds $>200 \mathrm{rpm}$. These trends were not seen when the polymer matrix was processed with a barrel temperature of $130^{\circ} \mathrm{C}$. Instead, the die pressure did not decrease significantly at screw speeds $<600 \mathrm{rpm}$. Torque values saw a steady decrease across the entire screw speed range from $47 \%$ at $50 \mathrm{rpm}$ to $28 \%$ at $600 \mathrm{rpm}$. A shear induced rise in product temperature was observed across the entire screw speed range (Figure $4 \mathrm{C}$ ), with the highest rise seen for the lowest $\left(130^{\circ} \mathrm{C}\right.$ ) process temperature increasing by $8.8^{\circ} \mathrm{C}$ at $600 \mathrm{rpm}$. In order to prevent this shear induced rise in product temperature (to avert MFA form change), the lowest screw speed of $50 \mathrm{rpm}$ was selected.

The lowest processing temperature and associated product temperature for SOL15SORB was determined at $50 \mathrm{rpm}$ and $0.1 \mathrm{~kg} / \mathrm{h}$ feed rate at $130^{\circ} \mathrm{C}$ (barrel) with the filament extruding as a clear, smooth strand (Figure 6A). This was in good agreement with the results obtained from the oscillatory temperature and frequency sweep experiments. The associated torque and pressure values were well within the maximum limit of the Process 11 extruder with $47 \pm 0.6 \%$ torque and a die pressure of $43 \pm$ 2.3 bar (Figure 4).

In subsequent HME trials for 5OMFA-SOL15SORB, the lowest extrusion temperature was $125^{\circ} \mathrm{C}$. Torque values were significantly lower ( $30 \pm 0.7 \%$ at $50 \mathrm{rpm})$ compared to the polymer matrix only. An increase in screw speed saw a gradual modest decrease in torque, dropping by only $5.8 \%$ at 400 rpm (Figure 4), compared to a $15 \%$ drop for the polymer matrix only $\left(130^{\circ} \mathrm{C}\right)$. The lower torque values were very likely due to a dilution effect and a plasticisation effect of MFA in the polymer matrix.

In contrast, the die pressure for 50MFA-SOL15SORB extrusion was considerably higher (64 bar at 50 $\mathrm{rpm}$ ) than the polymer matrix only (43 bar at $50 \mathrm{rpm}$ ) and exhibited significant variation ( \pm 7.4 bar) (Figure 4). These high pressures decreased as the screw speed was increased, seen as a drop in 19.4 bar at $400 \mathrm{rpm}$ (compared to 9 bar for the polymer matrix only). The high vapour pressure of MFA at elevated temperatures 22 and the tendency to sublime ${ }^{22,23}$ may explain the rise in die pressure during extrusion of the 50MFA-SOL15SORB mixture. In addition, a shear induced rise in product temperature was observed $\left(3^{\circ} \mathrm{C}\right.$ at $\left.400 \mathrm{rpm}\right)$, which was notably lower than the rise seen in the polymer matrix only $\left(6^{\circ} \mathrm{C}\right.$ at $\left.400 \mathrm{rpm}\right)$. In order to prevent further increase in product temperature (and retain MFA form I), the screw speed of $600 \mathrm{rpm}$ was not investigated.

The lowest processing and associated product temperature for 50MFA-SOL15SORB was $125^{\circ} \mathrm{C}(50$ $\mathrm{rpm}, 0.1 \mathrm{~kg} / \mathrm{h}$ feed rate), only marginally lower than the polymer matrix only. The filament was white in appearance, indicative of the presence of crystalline MFA (Figure 6B).

The filament diameter was affected by process temperature and screw speed. SOL15SORB filaments extruded at $130{ }^{\circ} \mathrm{C}$ were larger in diameter compared to filaments extruded at $140{ }^{\circ} \mathrm{C}$. An increase in 
screw speed saw a modest increase in diameter at $130{ }^{\circ} \mathrm{C}$, but a decrease at $140{ }^{\circ} \mathrm{C}$. This was in good agreement with the viscoelastic properties determined in the oscillatory frequency sweep experiments: the polymer matrix showed a higher storage modulus (elastic behaviour, G') and shear induced increase in storage modulus (and therefore die swell) at $130{ }^{\circ} \mathrm{C}$ compared to $140{ }^{\circ} \mathrm{C}$ (Figure 3B, Figure S 1).

50MFA-SOL15SORB behaved similar to the polymer matrix extruded at $130{ }^{\circ} \mathrm{C}$. At higher shear $(400$ $\mathrm{rpm}$ ) a considerable increase in filament diameter was observed. HME trials at $600 \mathrm{rpm}$ were not performed for this formulation.

\subsection{DSC}

Thermal analysis of MFA powder showed the transition of MFA form I to MFA form II at $172.8^{\circ} \mathrm{C}$, with a subsequent melting endotherm of MFA form II at $233^{\circ} \mathrm{C}$ (Figure 7). For the physical mixture of Soluplus ${ }^{\circledR}$ and $15 \%$ (w/w) Sorbitol, two thermal events were observed: a polymer $\operatorname{Tg}$ at $\sim 66^{\circ} \mathrm{C}$ and a Sorbitol melting endotherm at $98^{\circ} \mathrm{C}$. The 50MFA-SOL15SORB PM showed similar thermal events, but also a MFA transition at $174.4^{\circ} \mathrm{C}$, similar to neat MFA, and a melting endotherm shifted to significantly lower temperature of $214.9^{\circ} \mathrm{C}$. Extrudates presented as homogenous systems with the absence of a sorbitol melting peak. Instead, a single $\mathrm{Tg}$ of $47.7^{\circ} \mathrm{C}$ was observed for SOL15SORB and $46.7^{\circ} \mathrm{C}$ for 50MFA-SOL15SORB. MFA transition and melting temperatures were significantly reduced in the extrudate to $144.7^{\circ} \mathrm{C}$ and $192.4^{\circ} \mathrm{C}$, respectively.

\subsection{FTIR}

FTIR analysis was performed on the PM to confirm the presence of MFA form I in the raw material mixtures and in order to assess whether MFA phase transformation had occurred during the HME process. An important spectral feature to distinguish MFA polymorphs can be the N-H stretching band of the amino group which is associated with an intramolecular hydrogen bond with the carboxyl group $^{26}$. The stable MFA form I polymorph displays this band at $3312 \mathrm{~cm}^{-1}$, whereas the conformational changes in form II shift this stretch to an energetically higher band at $3353 \mathrm{~cm}^{-1}$. The $\mathrm{N}-\mathrm{H}$ stretch for the physical mixture and extrudate was observed at $3308 \mathrm{~cm}^{-1}$ (Figure 8), in line with literature values for MFA form $\mathrm{I}^{26}$.

\subsection{Mechanical testing}

Mechanical properties of extrudates are affected by the solid state of the API in the formulation and can significantly affect post-processing steps of solidified extrudates. The flexural modulus is the elastic (reversible) stiffness of a material and is graphically represented as the initial linear region on the stress strain graph. The maximum stress is representative of the strength of a material. Although the polymer matrix extrudate and the API loaded extrudate show a similar elastic stiffness, the API containing filament shows significant reduction in strength (16.5 $\mathrm{MPa}$ ) compared to the polymer matrix only (33.0 MPa) (Figure 9). This is also reflected in the energy requirements for material failure, the modulus of toughness, which is significantly lower for the extrudate containing MFA.

\subsection{SEM}

Extrudate cross sectional areas and outer surfaces were investigated by SEM analysis at 30x, 500x and 2000x magnification. The SOL15SORB extrudate was seen as a homogenous, smooth system on the face and the outer surface (Figure 10.). The addition of $50 \%$ (w/w) MFA to the system resulted in an abundance of pores in the extrudate. These were predominantly observed in the core of the extrudate but to a lesser degree on the outer surface as well. The absence of pores on the outer surface may be due to MFA sublimation from the outer surface, aided by the low complex viscosity and dominating viscous behaviour of the polymer matrix, as the filament exits the hot HME die. Whilst the outer surface of the SOL15SORB filament appeared smooth and showed no evidence of pores, the $50 \%(\mathrm{w} / \mathrm{w})$ drug loaded filaments appeared rougher and showed evidence of crystalline material. Based on the SEM images, the crystalline domains were approximately $<10 \mu \mathrm{m}$ in length. 


\subsection{Release testing USP 37}

In vitro drug release of $250 \mathrm{mg}$ MFA dose of a commercial powder fill formulation (Pharmavit Limited (PVL), Batch 4348) and pelletized 50MFA-SOL15SORB extrudate was performed, based on the USP37 dissolution method. Both formulations comply with the immediate release requirements for a MFA product with all 6 capsules releasing $\geq 85 \%$ at 45 min (Figure 11). However, comparing both dissolution profiles based on the difference (f1) and similarity (f2) factor method ${ }^{21}$, both profiles showed a high $\mathrm{f} 1$ (difference) value exceeding the criteria for similarity $(\leq 15)$ and an $\mathrm{f} 2$ (similarity) factor below to the sameness level $(50-100)$. The commercial product showed large variability between tested capsules with standard deviations of up to $17 \%$ and took the full $45 \mathrm{~min}$ to achieve the required drug release. Drug release from the in house produced formulation was faster, reaching $85 \%$ drug release at 35 minutes. The release profile shows significantly higher consistency with substantially lower standard deviation of $6 \%$. 


\section{Discussion}

The aim of this study was to develop an immediate release formulation for a BCS class Ila API, MFA, with improved consistency for its drug release with a simplified formulation compared to a commercially available MFA product.

Solid dispersions have shown to greatly increase the solubility of BCS class lla drugs ${ }^{14,18}$. A crystalline solid dispersion formulation was chosen in order to improve the consistency in drug release, by addressing critical parameters for complete and consistent drug dissolution of BCS class II drugs, such as reduction in particle size, surface area and improved wettability $3,4,14$. Preparation of solid dispersions by hot melt extrusion generally achieve higher drug loadings compared to other methods $^{12}$. In case of MFA and Soluplus ${ }^{\circledR}$, up to $40 \%(\mathrm{w} / \mathrm{w})$ drug loading for ASD and $50 \%(\mathrm{w} / \mathrm{w})$ drug loading of a mixture of MFA form II and amorphous MFA have been reported ${ }^{12,14}$. Since the lowest single dose of MFA dose forms is $250 \mathrm{mg}$, a high drug loaded formulation was required and therefore a hot melt extrusion process selected.

The rational for polymer matrix selection was based on targeting the lowest possible HME processing temperature in order to avoid dissolution of MFA in the polymer matrix and retain crystallinity with the stable polymorphic form of MFA (form I). Soluplus ${ }^{\circledR}$, a polyvinyl caprolactam-polyvinyl acetatepolyethylene glycol graft copolymer, was selected based on the reported low HME processing temperature ${ }^{24}$. In order to further reduce the complex viscosity-temperature dependence of the polymer, $15 \%(\mathrm{w} / \mathrm{w})$ plasticiser, D-Sorbitol, was added to the polymer matrix. Typically, HME process temperature selection is based on the $\mathrm{Tg}$ of the polymer plus $20-40^{\circ} \mathrm{C}^{27}$, resulting in a wide range of potential processing temperatures and larger quantities of material required for process development. This approach also lacks information on the viscoelastic properties of materials: the tendency of material to flow at temperature and under shear. The addition of plasticiser to the polymer to reduce the complex viscosity and therefore HME processing temperature proved successful. The evaluation of viscoelastic properties for SOL15SORB provided a more detailed insight into the polymer melt behaviour in the extruder and guided screw speed selection for the HME process by highlighting the impact of processing parameters on post processing steps; e.g. rise in product temperature (Figure 4C) due to viscous dissipation (Figure 3B) and die swell (Figure 5) due to a shear induced increase in storage modulus (elastic behaviour) of the polymer (Figure 3B, Figure S 1).

Based on a complex viscosity range ideal for HME on small scale extruders ${ }^{24}$, the rheology screen was in good agreement with the lowest possible HME processing temperature for both neat Soluplus ${ }^{\circledR}$ and SOL15SORB $\left(145^{\circ} \mathrm{C}\right.$ and $130^{\circ} \mathrm{C}$, respectively) (Figure 2, Figure 3 ) and resulted in substantially less required material in establishing suitable process parameters. This is in agreement with other studies on rheology guided selection of HME processing conditions which have been successful for API's which are soluble in the carrier matrix ${ }^{25,28,29}$. In the case of MFA, exhibiting low solubility in the polymer matrix, rheology screening for HME processing parameters proved unsuccessful (due to poor repeatability) and highlighted the limitations of rheological screening assays.

Crystallinity of the 50MFA-SOL15SORB extrudate was observed visually in the white appearance (Figure 6), but was also confirmed by thermal analysis (Figure 7) and $\mathrm{N}-\mathrm{H}$ stretching bands characteristic of MFA form I by FTIR spectroscopy (Figure 8). A significant MFA melting point depression in the MFA extrudate indicated strong API-polymer interactions. In addition, no $\mathrm{Tg}$ depression was observed for the MFA extrudate compared to the polymer matrix extrudate, suggesting the majority of MFA in the extrudate is presented in crystalline form.

Plasticisation effects, due to molecularly dispersed API in the polymer matrix, are commonly associated with $\mathrm{Tg}$ depression ${ }^{28}$, but have also been linked to a decrease in elastic stiffness of extrudates ${ }^{20}$. The absence of substantial $\mathrm{Tg}$ depression and lack of reduction in flexural modulus for MFA extrudates compared to matrix extrudates suggest a minimal presence of molecularly dispersed MFA in the extrudate. Alternative analytical techniques such as X-Ray Powder Diffraction or Terahertz Raman spectroscopy may be useful to assess the degree of amorphous contribution to the solid dispersions. Online Terahertz Raman spectroscopy has previously shown to be a robust method to determine the saturated solubility of crystalline active pharmaceutical ingredient (API) in polymeric 
matrices directly during hot melt extrusion ${ }^{19}$, and would be a useful tool to further characterise this CSD. Effects of an increase of crystalline content in extrudates has previously shown to affect mechanical properties of the material, seen as a decrease in strength and increase in product failure $^{20}$. Significantly lower strength and product failure (modulus of toughness) were observed for extrudates containing MFA (Figure 9). However, these effects may have been intensified by the highly porous internal structure of the MFA extrudate (Figure 10). The presence of a highly porous structure is not surprising since high vapour pressure of MFA at elevated temperatures has previously been reported $^{22}$ and was also seen as a significant rise in die pressure during hot melt extrusion (Figure 4). Similar observations regarding porosity in relation to drug loading of extrudates were made by SEM and Micro-CT analysis, with pores located in the core of the filament rather than the outer surface ${ }^{30}$. At micro-structural levels, different levels of density were detected in the extrudate, corresponding to air, API and polymer. A similar analysis for the 50MFA-SOL15SORB formulation would be interesting and aid better understanding of the homogeneity of the CSD. However, this type of analysis is often limited by low imaging contrast, making it difficult to distinguish between polymer and API.

Dissolution testing of the commercial powder capsule formulation showed significant variability between all tested capsules. The rate of dissolution of drugs from capsules has been described as a complex function of the rates of different processes, such as solution of the gelatine shell, penetration of water into the powder mass, de-aggregation of the powder mass and dissolution of the powder particles ${ }^{31}$. For BCS class Ila drugs in particular, particle size, surface area and wettability are critical in achieving complete drug release ${ }^{3,4,13}$. The substantial reduction in MFA particle size (Figure 10) in the extrudate compared to the raw material and the associated increase in surface area, combined with the strong API-polymer interaction promoting wettability of the API (as well as the high porosity of the extrudate (Figure 10)) are seen in a faster and significantly improved consistency in the drug release profile (Figure 11). This was confirmed with FDA guided statistical analysis of both release profiles. Darwich reported complete ( $95 \%$ ) drug release form an amorphous solid dispersion of MFASoluplus ${ }^{\circledR}$ within $15 \mathrm{~min}^{14}$. Although drug release from this type of formulation was faster owing to the amorphous nature of the drug, a one-year stability study saw slower and incomplete drug release. This highlights potential problems with the stability of amorphous solid dispersions.

\section{Conclusion}

Rheology guided HME process development allowed faster identification of suitable processing conditions, such as process temperature and screw speed, requiring less material. Although the rheology guided HME process development was successful, it also highlights the limitations of these screening assays for APIs with low solubility in the polymer.

The targeted immediate release profile for the CSD of MFA in Soluplus ${ }^{\circledR}$-Sorbitol formulation has been met, whilst the stable crystalline form (I) of MFA has been retained and the consistency of drug release has been significantly improved. The need for multiple excipients is avoided in this simplified formulation. Further investigations into the level of amorphous material and product stability need to be assessed.

This work supports the wider aim of the EPSRC Future Manufacturing Research HUB at CMAC to implement integrated continuous, laboratory scale manufacturing platforms. In this instance, crystal engineering of a model drug, MFA, coupled with polymer processing steps to deliver optimised physical properties for biopharmaceutics performance. It forms the basis for future work within the HUB, how coupling crystal engineering with polymer processing may facilitate future performance based design and continuous manufacture of structured particulate products.

\section{Declaration of Competing Interest}

The authors declare that they have no known competing financial interests or personal relationships that could have appeared to influence the work reported in this paper. 


\section{Acknowledgements}

The authors would like to acknowledge that this work was carried out in the CMAC National Facility supported by the EPSRC (Grant ref EP/P006965/1) and by UKRPIF (UK Research Partnership Fund) award from the Higher Education Funding Council for England (HEFCE) (Grant ref HH13054). G. W. Halbert is funded by Cancer Research UK (C149/A20496). We would like to thank the National Facility team and Corin Mack for their support in this project. We would also like to thank BASF for the donation of Soluplus ${ }^{\circledR}$ polymer and Cancer Research UK Formulation Unit for the donation of Licap ${ }^{\circledR}$ capsules.

\section{Data statement}

All data underpinning this publication are openly available from the University of Strathclyde KnowledgeBase at https://doi.org/10.15129/18916640-5b9d-4bea-afed-db2e1ca0f207. 


\section{References}

1. Abdul Mudalip SK, Abu Bakar MR, Jamal P, Adam F 2013. Solubility and Dissolution Thermodynamic Data of Mefenamic Acid Crystals in Different Classes of Organic Solvents. Journal of Chemical \& Engineering Data 58(12):3447-3452.

2. Nurhikmah W, Sumirtapura YC, Pamudji JS 2016. Dissolution Profile of Mefenamic Acid Solid Dosage Forms in Two Compendial and Biorelevant (FaSSIF) Media. Sci Pharm 84(1):181-190.

3. Butler JM, Dressman JB 2010. The Developability Classification System: Application of Biopharmaceutics Concepts to Formulation Development. Journal of Pharmaceutical Sciences 99(12):4940-4954.

4. Vasconcelos T, Sarmento B, Costa P 2007. Solid dispersions as strategy to improve oral bioavailability of poor water soluble drugs. Drug Discov Today 12(23-24):1068-1075.

5. Hummel D, Buchmann S 2000. Influence of mefenamic acid particle size on dissolution and bioavailability of tablets. PHARMAZEUTISCHE INDUSTRIE 62(6):452-456.

6. Iwasaki T, Takahara M, Sonoda R, Watano S 2007. Dry Grinding of Mefenamic Acid Particles for Enhancement of its Water Dissolution Rate. Particle \& Particle Systems Characterization 24(3):236-241.

7. Ullah I, Baloch MK, Ullah I, Mustaqeem M 2014. Enhancement in Aqueous Solubility of Mefenamic Acid using Micellar Solutions of Various Surfactants. Journal of Solution Chemistry 43(8):1360-1373.

8. Derle DV, Bele M, Kasliwal N 2008. In Vitro and In Vivo Evaluation of Mefenamic acid and its complexes with beta-Cyclodextrin and HP-beta-Cyclodextrin. Asian Journal of Pharmaceutics 2(1):30-34.

9. Gursoy RN, Benita S 2004. Self-emulsifying drug delivery systems (SEDDS) for improved oral delivery of lipophilic drugs. Biomed Pharmacother 58(3):173-182.

10. Sriamornsak P, Limmatvapirat S, Piriyaprasarth S, Mansukmanee P, Huang Z 2015. A new self-emulsifying formulation of mefenamic acid with enhanced drug dissolution. Asian Journal of Pharmaceutical Sciences 10(2):121-127.

11. Kumar M, Singh D, Bedi N 2019. Mefenamic acid-loaded solid SMEDDS: an innovative aspect for dose reduction and improved pharmacodynamic profile. Ther Deliv 10(1):21-36.

12. Alshehri SM, Park JB, Alsulays BB, Tiwari RV, Almutairy B, Alshetaili AS, Morott J, Shah S, Kulkarni V, Majumdar S, Martin ST, Mishra S, Wang L, Repka MA 2015. Mefenamic acid taste-masked oral disintegrating tablets with enhanced solubility via molecular interaction produced by hot melt extrusion technology. J Drug Deliv Sci Technol 27:18-27.

13. Rao KR, Nagabhushanam MV, Chowdary KP 2011. In vitro Dissolution Studies on Solid Dispersions of Mefenamic Acid. Indian J Pharm Sci 73(2):243-247.

14. Darwich M. 2015. Solubility/Bioavailability Enhancement and Modified Release Formulations of Poorly Water-Soluble Drugs. Institute for Pharmacy, ed., Berlin: Freie Universität Berlin.

15. Andrews GP, Zhai H, Tipping S, Jones DS 2009. Characterisation of the thermal, spectroscopic and drug dissolution properties of mefenamic acid and polyoxyethylene-polyoxypropylene solid dispersions. J Pharm Sci 98(12):4545-4556.

16. Tambosi G, Coelho PF, Luciano S, Lenschow ICS, Zétola M, Stulzer HK, Pezzini BR 2018. Challenges to improve the biopharmaceutical properties of poorly water-soluble drugs and the application of the solid dispersion technology. Matéria (Rio de Janeiro) 23.

17. Owusu-Ababio G, Ebube NK, Reams R, Habib M 1998. Comparative dissolution studies for mefenamic acid-polyethylene glycol solid dispersion systems and tablets. Pharm Dev Technol 3(3):405-412.

18. Zografi G, Newman A 2017. Interrelationships Between Structure and the Properties of Amorphous Solids of Pharmaceutical Interest. J Pharm Sci 106(1):5-27. 
19. Bordos E, Islam MT, Florence AJ, Halbert GW, Robertson J 2019. Use of Terahertz-Raman Spectroscopy to Determine Solubility of the Crystalline Active Pharmaceutical Ingredient in Polymeric Matrices during Hot Melt Extrusion. Mol Pharm 16(10):4361-4371.

20. Prasad E, Islam MT, Goodwin DJ, Megarry AJ, Halbert GW, Florence AJ, Robertson J 2019. Development of a hot-melt extrusion (HME) process to produce drug loaded Affinisol ${ }^{\mathrm{TM}} 15 \mathrm{LV}$ filaments for fused filament fabrication (FFF) 3D printing. Additive Manufacturing 29:100776. 21. 1997. Dissolution Testing of Immediate Release Solid Oral Dosage Forms. ed.

22. Surov AO, Terekhova IV, Bauer-Brandl A, Perlovich GL 2009. Thermodynamic and Structural Aspects of Some Fenamate Molecular Crystals. Crystal Growth \& Design 9(7):3265-3272.

23. SeethaLekshmi S, Guru Row TN 2012. Conformational Polymorphism in a Non-steroidal Antiinflammatory Drug, Mefenamic Acid. Crystal Growth \& Design 12(8):4283-4289.

24. Kolter K, Karl M, Gryczke A. 2012. Hot-Melt Extrusion with BASF Pharma Polymers. 2nd Revised and Enlarged Edition ed., Ludwigshafen, Germany: BASF The Chemical Company.

25. Aho J, Boetker JP, Baldursdottir S, Rantanen J 2015. Rheology as a tool for evaluation of melt processability of innovative dosage forms. Int J Pharm 494(2):623-642.

26. Abbas N, Oswald IDH, Pulham CR 2017. Accessing Mefenamic Acid Form II through HighPressure Recrystallisation. Pharmaceutics 9(2).

27. Kulkarni C, Kelly A, Gough T, Jadhav V, Singh K, Paradkar A 2017. Application of hot melt extrusion for improving bioavailability of artemisinin a thermolabile drug. Drug Development and Industrial Pharmacy 44:1-9.

28. Yang F, Su Y, Zhang J, DiNunzio J, Leone A, Huang C, Brown CD 2016. Rheology Guided Rational Selection of Processing Temperature To Prepare Copovidone-Nifedipine Amorphous Solid Dispersions via Hot Melt Extrusion (HME). Mol Pharm 13(10):3494-3505.

29. Gupta SS, Parikh T, Meena AK, Mahajan N, Vitez I, Serajuddin ATM 2015. Effect of carbamazepine on viscoelastic properties and hot melt extrudability of Soluplus (R). Int J Pharm 478(1):232-239.

30. Martinez-Marcos L, Lamprou DA, McBurney RT, Halbert GW 2016. A novel hot-melt extrusion formulation of albendazole for increasing dissolution properties. International Journal of Pharmaceutics 499(1):175-185.

31. Shinkuma D, Hamaguchi T, Yamanaka Y, Mizuno N 1984. Correlation between dissolution rate and bioavailability of different commercial mefenamic acid capsules. International Journal of Pharmaceutics 21(2):187-200. 


\section{Table of Figures}

Figure 1: Thermo 11 (length $(L)$ to diameter $(D)$ ratio of $403 / 4$ ) screw configuration: 14 feed screws, $6 x$ $60^{\circ} \mathrm{F}$ mixing elements, 7 feed screws, $3 \times 30^{\circ} \mathrm{F}, 3 \times 60^{\circ} \mathrm{F}, 4 \times 90^{\circ}$ mixing elements, 13 feed screws, discharge element.

Figure 2: Oscillatory temperature sweep: Complex viscosity Soluplus ${ }^{\circledR}$ (circle) and SOL15SORB PM (square) versus temperature. Complex viscosity suitable fo hot melt extrusion on $11 \mathrm{~mm}$ extrudershaded grey.

Figure 3: Oscillatory frequency sweep: A) complex viscosity and B) Storage (filled) and Loss (open) modulus versus angular frequency of SOL15SORB PM: $120{ }^{\circ} \mathrm{C}$ - blue diamond, $130{ }^{\circ} \mathrm{C}$ - orange square, $140{ }^{\circ} \mathrm{C}$ - black triangle. Complex viscosity suitable for extrusion on $11 \mathrm{~mm}$ extruder - shaded grey. B) Vertical line indicates G'-G" crossover at $120^{\circ} \mathrm{C}$ - solid blue line and at $130{ }^{\circ} \mathrm{C}$ - dashed orange line.

Figure 4: HME process data: A) die pressure versus screw speed, B) torque versus screw speed and C) rise in product temperature versus screw speed; Barrel temperature: SOL $15 S O R B 140{ }^{\circ} \mathrm{C}-$ black triangle / white bar, SOL15SORB $130^{\circ} \mathrm{C}$ - orange square / bar, 50MFA-SOL15SORB $125^{\circ} \mathrm{C}-$ purple circle / bar (processed from 50 - 400 rpm only); torque - straight lines, die pressure - dashed lines.

Figure 5: Die swell of SOL15SORB and 50MFA-SOL15SORB versus screw speed. Process temperature SOL15SORB $140{ }^{\circ} \mathrm{C}$ - white and $130^{\circ} \mathrm{C}$ - orange; 5OMFA-SOL $15 S O R B 125^{\circ} \mathrm{C}-$ purple (processed from $50-400 \mathrm{rpm}$ only).

Figure 6: Filament extrudates: A) SOL15SORB and B) 50 MFA-SOL15SORB (0.1 kg/h feed rate, 50 rpm, process temperatures SOL $\left.15 S O R B-130^{\circ} \mathrm{C}, 50 M F A-S O L 15 S O R B-125^{\circ} \mathrm{C}\right)$.

Figure 7: Thermogram of MFA, physical mixtures (PM) and extrudates (EX) of SOL15SORB and 50MFA-SOL15SORB: Heating cycle from $0-250^{\circ} \mathrm{C}$ at $20^{\circ} \mathrm{C} / \mathrm{min}$. From top to bottom: MFA powder - black solid line; SOL15SORB: PM - blue solid line, EX - blue dashed line; 50MFA-SOL15SORB: $P M$ - red solid line, EX - red dashed line; $(n=2)$.

Figure 8: FTIR N-H stretch band of MFA form II (red, N-H 3344.04cm-1) and MFA form I (dark blue, NH $3307.71 \mathrm{~cm}^{-1}$ ), 50MFA-SOL15SORB PM (dark green) and extrudate (turquoise), SOL15SORB extrudate (purple).

Figure 9: Mechanical properties of extruded filaments: A) Flexural modulus (FM, white), Strain at maximum stress (S, dark grey), B) Maximum stress (MS, light grey), Modulus of toughness (MoT, black); independent two tailed t-test (mean \pm standard deviation, $n=5)$ with equal variation (MS) and unequal variation (FM, S, MoT) showed significant difference ( $p$-value $\leq 0.05)$ for all mechanical properties except FM).

Figure 10: SEM images of extrudate cross sectional area and outer surfaces at a) x30, b) x500 and c) x2000 magnification. Cross sectional area: 1) SOL15SORB, 2) 50MFA-SOL15SORB. Outer surface: 3) SOL15SORB, 4) 5OMFA-SOL15SORB.

Figure 11: In vitro drug release of $250 \mathrm{mg}$ MFA dose of a commercial powder fill capsule formulation (orange square, Pharmavit Limited (PVL), Batch 4348, $n=6$ ) and pelletised 50MFA-SOL15SORB extrudate in Licap ${ }^{\circledR}$ capsule (blue triangle, $n=6$ ) based on the USP37 dissolution method. Dashed line - $85 \%$ drug release.

\section{Table of Tables}

Table 1: HPLC gradient method: mobile phase composition.

Table 2: Particle size distribution of Mefenamic acid (Sigma) raw material (QicPic). 


\section{Supplementary data}

Figure S 1: SOL15SORB PM oscillatory frequency sweep: tan delta (Loss modulus G" / Storange modulus $\left.\mathrm{G}^{\prime}\right)$ versus angular frequency $\left(160^{\circ} \mathrm{C}\right.$ - diamond, $150^{\circ} \mathrm{C}$ - circle, $140^{\circ} \mathrm{C}$ - triangle, $130^{\circ} \mathrm{C}-$ square, $120^{\circ} \mathrm{C}$ - cross). G" = G'-long-dash line; G' / G" crossover: $120^{\circ} \mathrm{C}$ dash-dot line, $130^{\circ} \mathrm{C}-$ dotted line. 
Table 1: HPLC gradient method: mobile phase composition.

\begin{tabular}{|l|c|c|}
\hline Time $(\mathrm{min})$ & Mobile Phase A (\%) & Mobile Phase B (\%) \\
\hline 0 & 95 & 5 \\
\hline 4.5 & 0 & 100 \\
\hline 7.5 & 0 & 100 \\
\hline 7.51 & 95 & 5 \\
\hline 9 & 95 & 5 \\
\hline
\end{tabular}


Table 2: Particle size distribution of Mefenamic acid (Sigma) raw material (QicPic).

\begin{tabular}{|l|c|c|}
\hline D-Values & $\begin{array}{c}\text { Mean diameter } \\
(\mu \mathrm{m})\end{array}$ & $\begin{array}{c}\text { standard } \\
\text { deviation }\end{array}$ \\
\hline D10 & 39.3 & 1.4 \\
\hline D16 & 53.7 & 2.5 \\
\hline D50 & 151.9 & 5.9 \\
\hline D84 & 315.6 & 8.8 \\
\hline D90 & 371.7 & 6.8 \\
\hline D99 & 559.2 & 11.9 \\
\hline
\end{tabular}




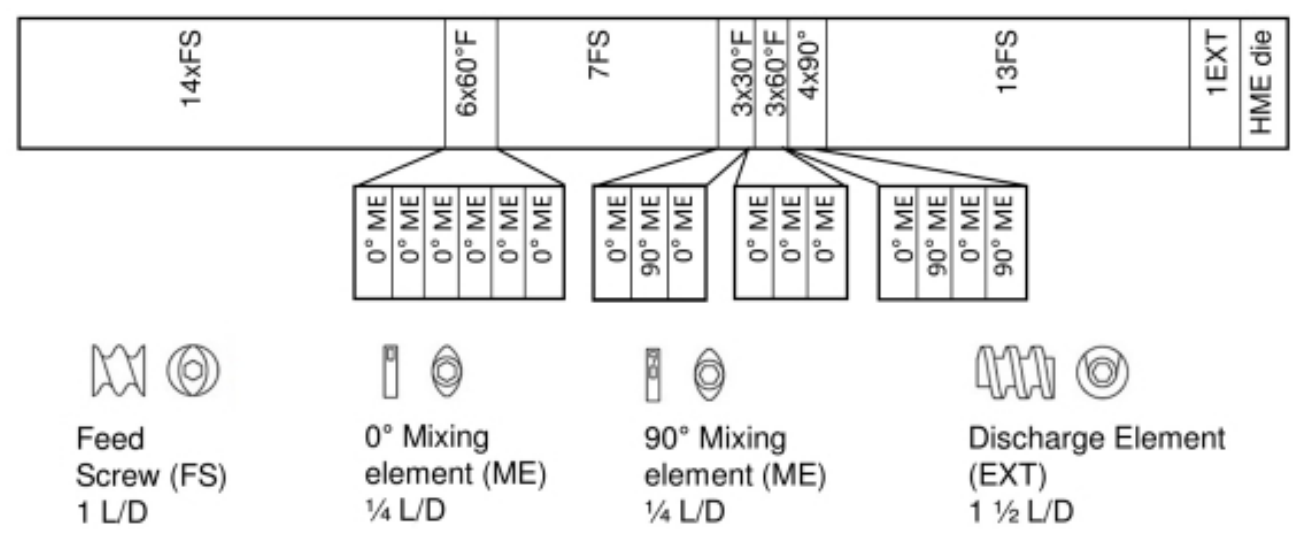

Thermo 11 (length (L) to diameter (D) ratio of $403 / 4$ ) screw configuration: 14 feed screws, $6 \times 60^{\circ} \mathrm{F}$ mixing elements, 7 feed screws, $3 \times 30^{\circ} \mathrm{F}, 3 \times 60^{\circ} \mathrm{F}, 4 \times 90^{\circ}$ mixing elements, 13 feed screws, discharge element.

$48 \times 19 \mathrm{~mm}(300 \times 300$ DPI $)$ 


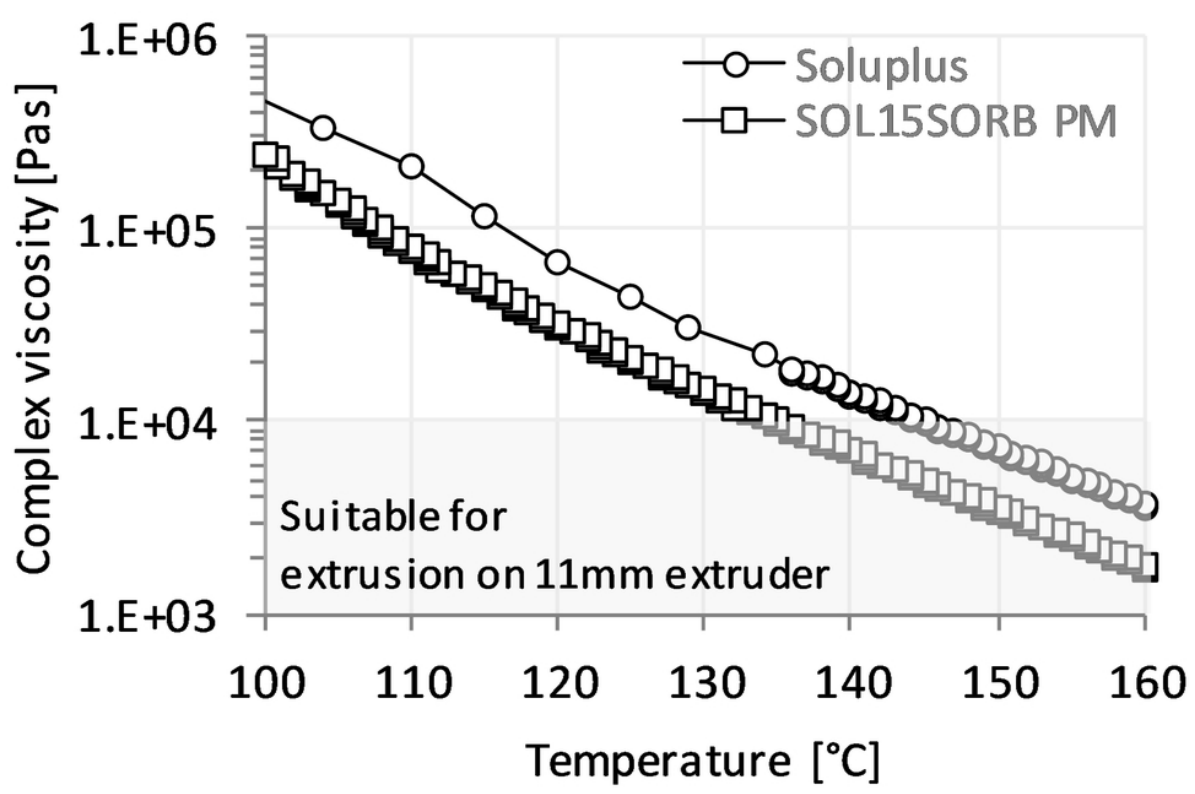

Oscillatory temperature sweep: Complex viscosity Soluplus ${ }^{\circledR}$ (circle) and SOL15SORB PM (square) versus temperature. Complex viscosity suitable for hot melt extrusion on $11 \mathrm{~mm}$ extruder - shaded grey.

$89 \times 59 \mathrm{~mm}(300 \times 300$ DPI $)$ 

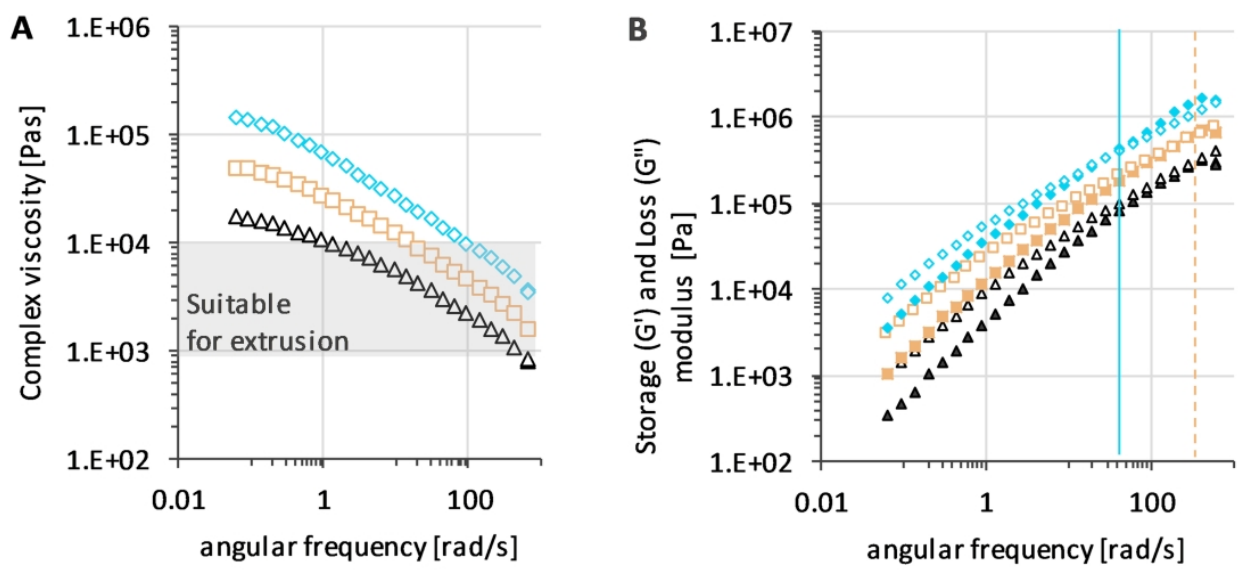

Oscillatory frequency sweep: A) complex viscosity and B) Storage (filled) and Loss (open) modulus versus angular frequency of SOL15SORB PM: $120^{\circ} \mathrm{C}$ - blue diamond, $130^{\circ} \mathrm{C}$ - orange square, $140{ }^{\circ} \mathrm{C}$ - black triangle. Complex viscosity suitable for extrusion on $11 \mathrm{~mm}$ extruder - shaded grey. B) Vertical line indicates $\mathrm{G}^{\prime}-\mathrm{G}^{\prime \prime}$ crossover at $120^{\circ} \mathrm{C}$ - solid blue line and at $130{ }^{\circ} \mathrm{C}$ - dashed orange line. 

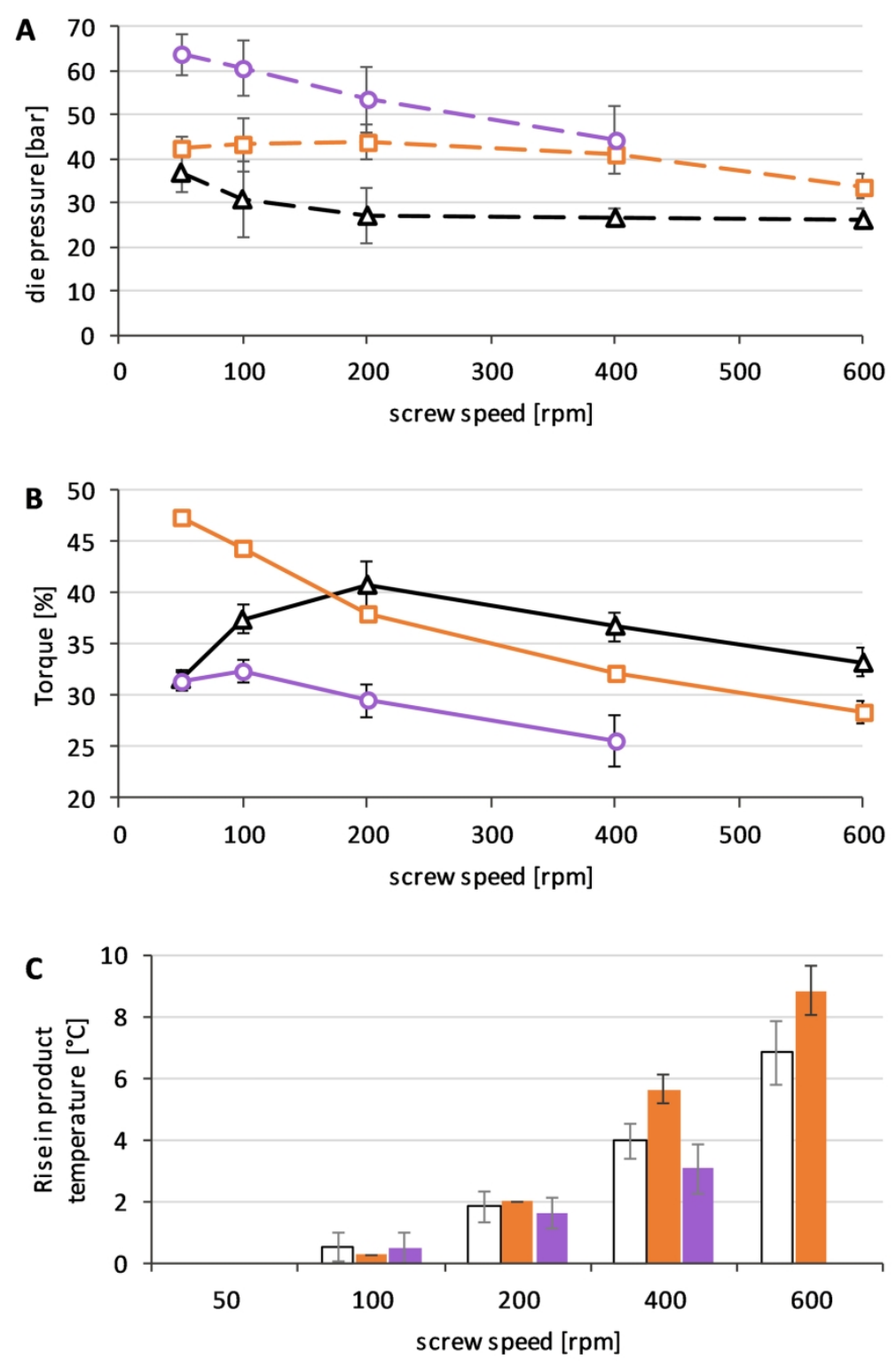

HME process data: A) die pressure versus screw speed, B) torque versus screw speed and C) rise in product temperature versus screw speed; Barrel temperature: SOL15SORB $140^{\circ} \mathrm{C}$ - black triangle / white bar, SOL15SORB $130^{\circ} \mathrm{C}$ - orange square / bar, 50MFA-SOL15SORB $125^{\circ} \mathrm{C}$ - purple circle / bar (processed from 50 - $400 \mathrm{rpm}$ only); torque - straight lines, die pressure - dashed lines. 


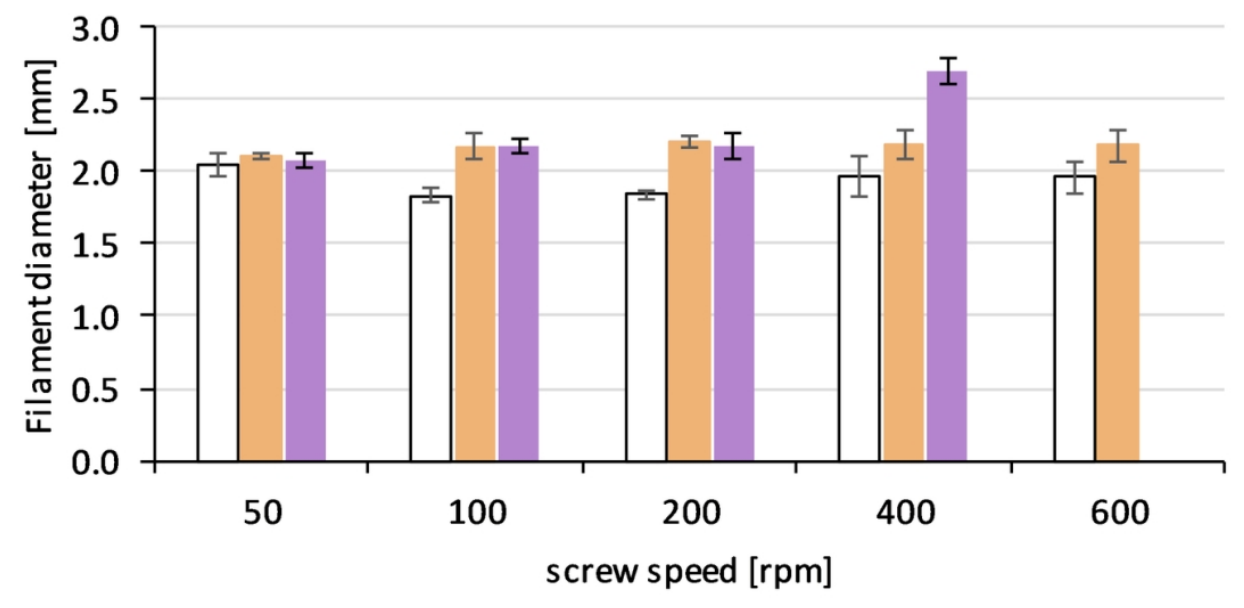

Die swell of SOL15SORB and 5OMFA-SOL15SORB versus screw speed. Process temperature SOL15SORB 140 ${ }^{\circ} \mathrm{C}$ - white and $130^{\circ} \mathrm{C}$ - orange; 5OMFA-SOL15SORB $125^{\circ} \mathrm{C}$ - purple (processed from 50 - $400 \mathrm{rpm}$ only). $119 \times 59 \mathrm{~mm}(300 \times 300 \mathrm{DPI})$ 


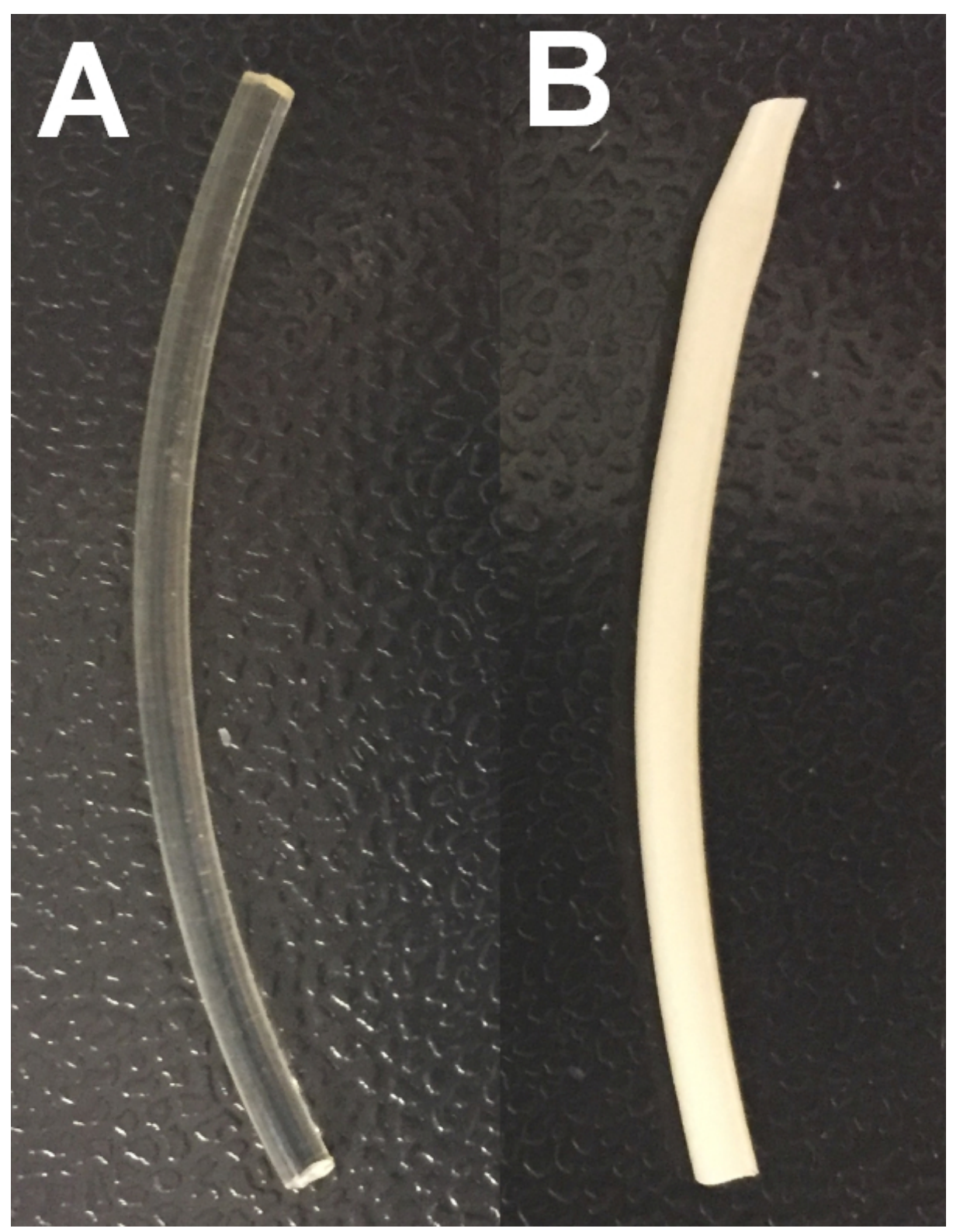

Filament extrudates: A) SOL15SORB and B) 50 MFA-SOL15SORB $(0.1 \mathrm{~kg} / \mathrm{h}$ feed rate, $50 \mathrm{rpm}$, process temperatures SOL15SORB $-130^{\circ} \mathrm{C}$, 5OMFA-SOL15SORB $\left.-125^{\circ} \mathrm{C}\right)$.

$30 \times 39 \mathrm{~mm}(500 \times 500 \mathrm{DPI})$ 


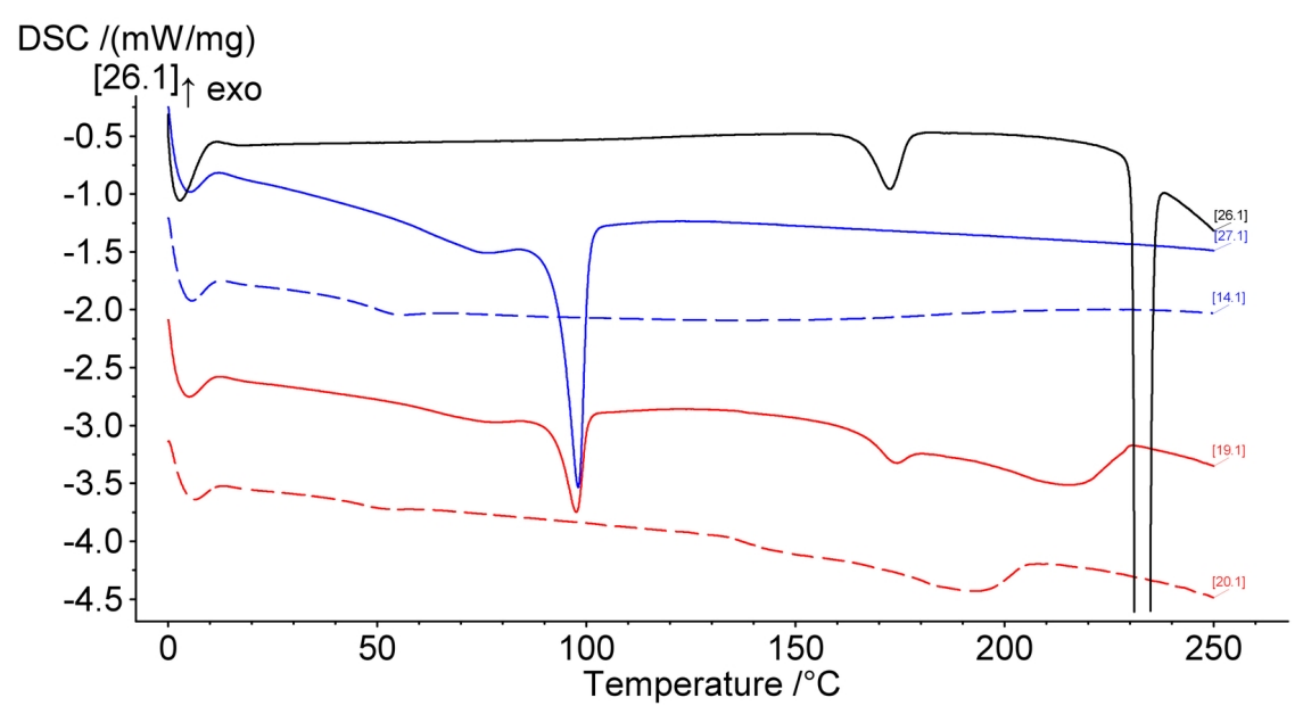

Thermogram of MFA, physical mixtures (PM) and extrudates (EX) of SOL15SORB and 50MFA-SOL15SORB: Heating cycle from $0-250^{\circ} \mathrm{C}$ at $20^{\circ} \mathrm{C} / \mathrm{min}$. From top to bottom: MFA powder - black solid line; SOL15SORB: PM - blue solid line, EX - blue dashed line; 5OMFA-SOL15SORB: PM - red solid line, EX - red dashed line; $(n=2)$.

$139 \times 80 \mathrm{~mm}(300 \times 300 \mathrm{DPI})$ 


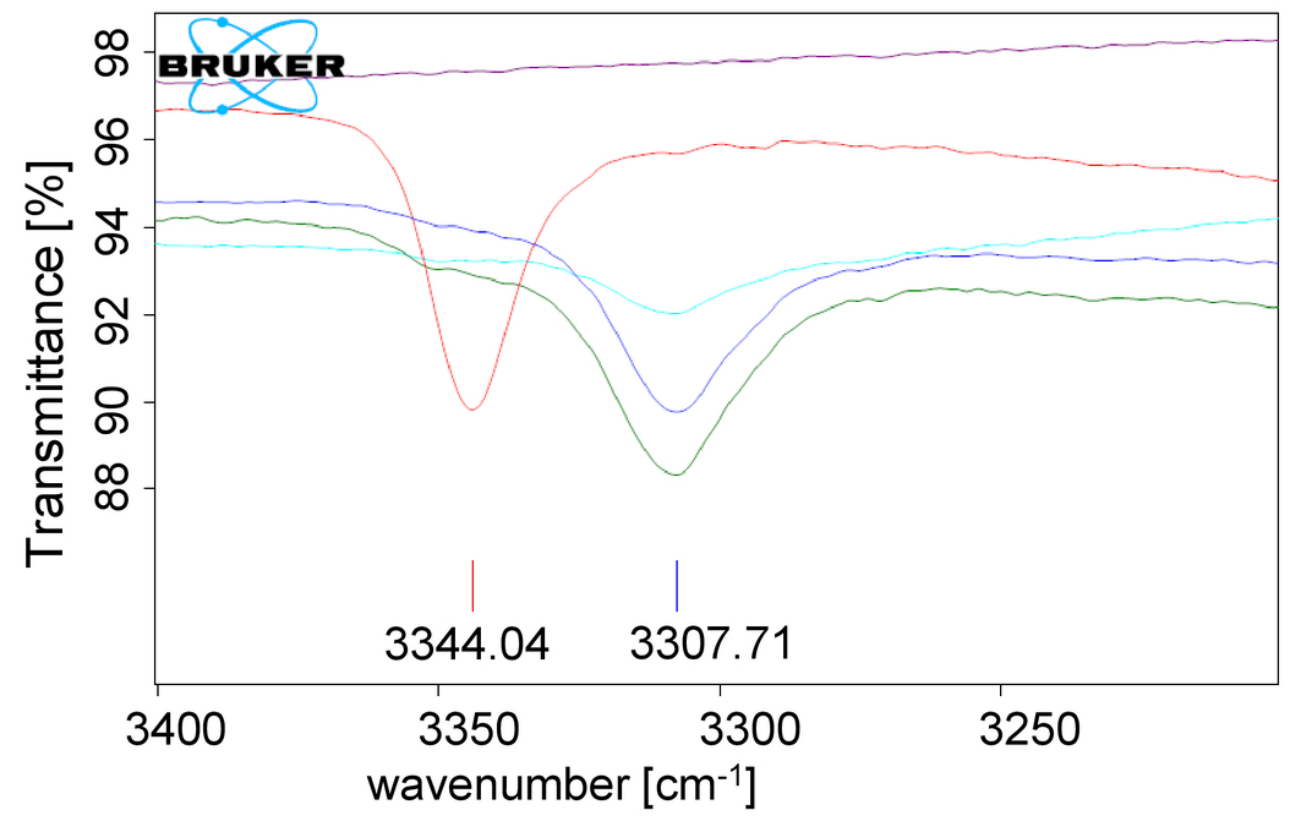

FTIR N-H stretch band of MFA form II (red, N-H 3344.04cm-1) and MFA form I (dark blue, N-H $3307.71 \mathrm{~cm}^{-}$ ${ }^{1}$ ), 50MFA-SOL15SORB PM (dark green) and extrudate (turquoise), SOL15SORB extrudate (purple).

$90 \times 60 \mathrm{~mm}(300 \times 300$ DPI $)$ 

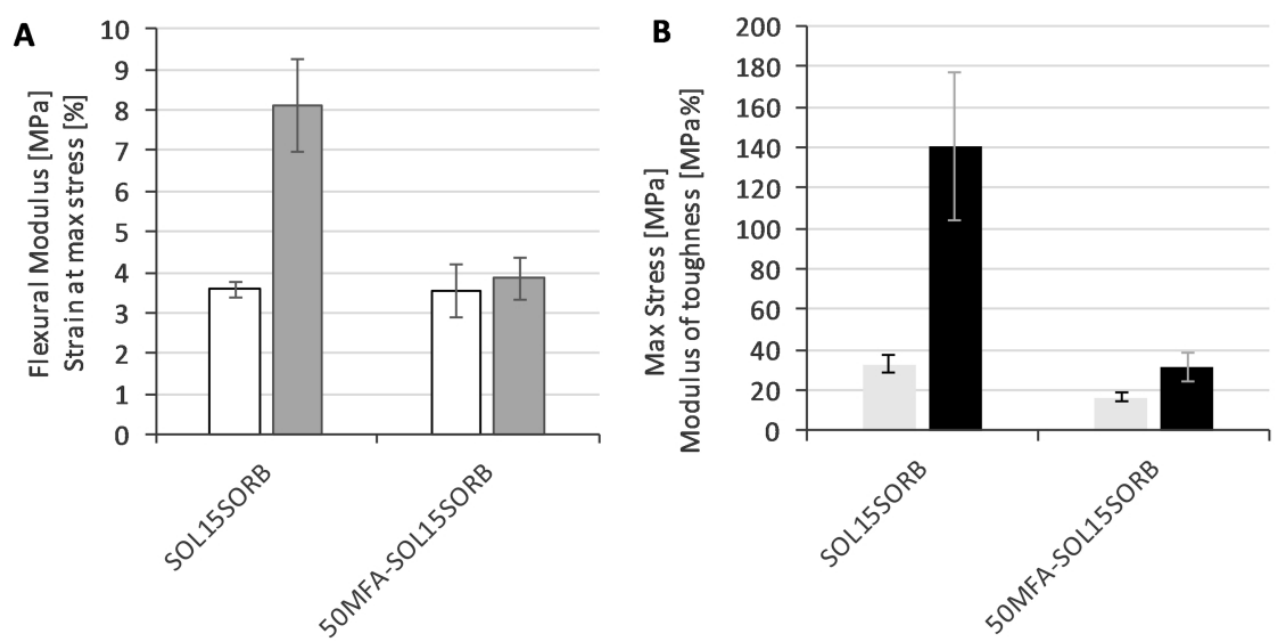

Mechanical properties of extruded filaments: A) Flexural modulus (FM, white), Strain at maximum stress (S, dark grey), B) Maximum stress (MS, light grey), Modulus of toughness (MoT, black); independent two tailed t-test (mean \pm standard deviation, $n=5$ ) with equal variation (MS) and unequal variation (FM, S, MoT) showed significant difference $(p-v a l u e ~ \leq 0.05)$ for all mechanical properties except FM).

$198 \times 100 \mathrm{~mm}(500 \times 500 \mathrm{DPI})$ 


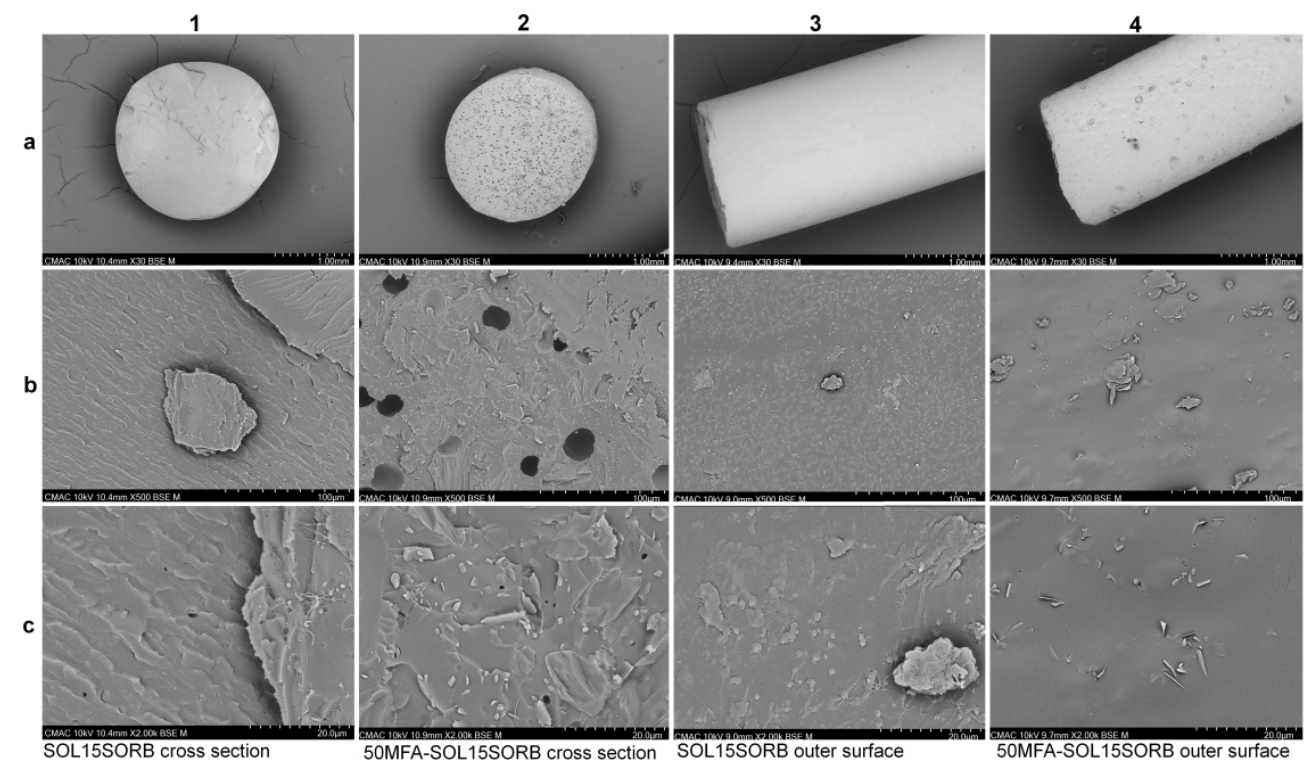

SEM images of extrudate cross sectional area and outer surfaces at a) $\times 30$, b) $\times 500$ and c) $\times 2000$ magnification. Cross sectional area: 1) SOL15SORB, 2) 50MFA-SOL15SORB. Outer surface: 3) SOL15SORB, 4) 5OMFA-SOL15SORB.

$279 \times 160 \mathrm{~mm}(500 \times 500 \mathrm{DPI})$ 


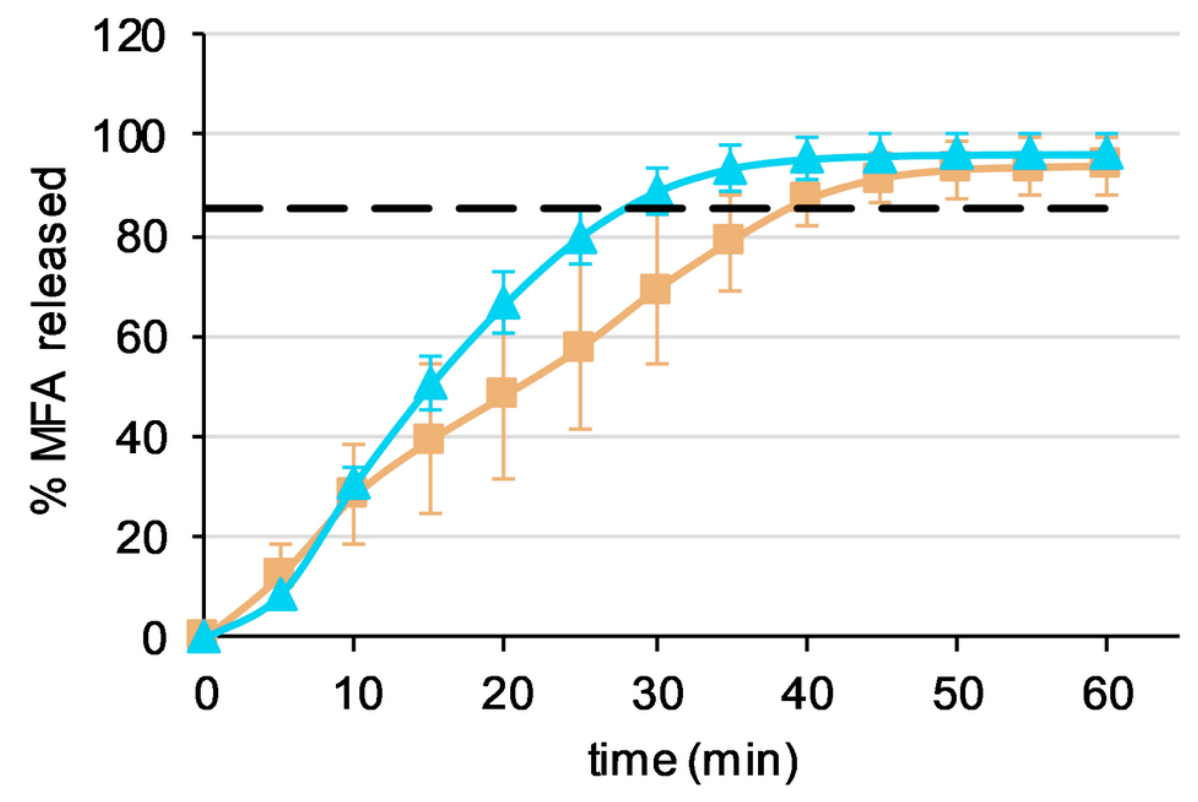

In vitro drug release of $250 \mathrm{mg}$ MFA dose of a commercial powder fill capsule formulation (orange square, Pharmavit Limited (PVL), Batch 4348, $\mathrm{n}=6$ ) and pelletised 50MFA-SOL15SORB extrudate in Licap ${ }^{\circledR}$ capsule (blue triangle, $\mathrm{n}=6$ ) based on the USP37 dissolution method. Dashed line $-85 \%$ drug release.

$89 \times 59 \mathrm{~mm}(300 \times 300 \mathrm{DPI})$ 


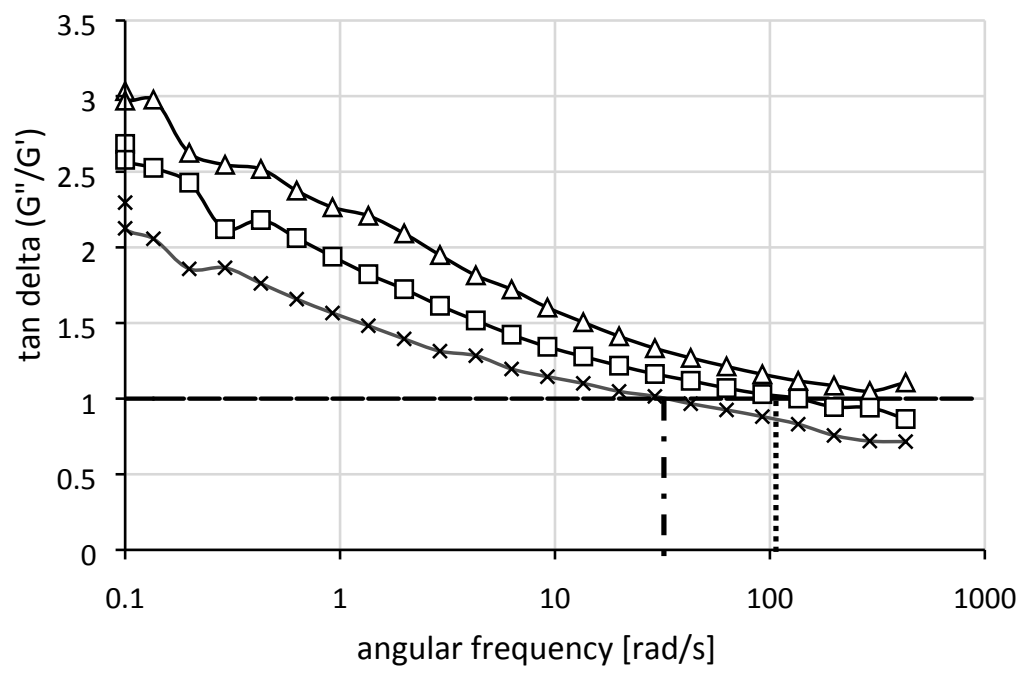

Figure S 1: SOL15SORB PM oscillatory frequency sweep: tan delta (Loss modulus G" / Storange modulus G') versus angular frequency $\left(160^{\circ} \mathrm{C}\right.$ - diamond, $150^{\circ} \mathrm{C}$ - circle, $140^{\circ} \mathrm{C}$ - triangle, $130^{\circ} \mathrm{C}$ - square, $120^{\circ} \mathrm{C}$ - cross). $G^{\prime \prime}=G^{\prime}$ - long-dash line; G' / G" crossover: $120^{\circ} \mathrm{C}$ dash-dot line, $130^{\circ} \mathrm{C}$-dotted line. 
All data underpinning this publication are openly available from the University of Strathclyde KnowledgeBase at https://doi.org/10.15129/18916640-5b9d-4bea-afed-db2e1ca0f207.

Please note, this link is not live until the study has been accepted for publication. In the meantime, the data is available upon request from the authors (elke.prasad@strath.ac.uk). 